\title{
Joy of controller design: Controller design based on Kocaeli university's converter dynamics toolbox for MATLAB
}

\author{
Farzin Asadi ${ }^{1,}$ *, Nurettin Abut ${ }^{2}$, Ismet Kandilli ${ }^{3}$ \\ ${ }^{1}$ Mechatronics Engineering Department, Kocaeli University, Kocaeli, Turkey \\ ${ }^{2}$ Electrical Engineering Department, Kocaeli University, Kocaeli, Turkey \\ ${ }^{3}$ Electronics and Automation Department, Kocaeli University, Kocaeli, Turkey
}

\section{ART I C L E IN F O}

\section{Article history:}

Received 30 December 2016

Received in revised form

11 May 2017

Accepted 12 May 2017

Keywords:

Converter modeling

Small signal model

State space averaging

\begin{abstract}
A B S T R A C T
In this paper, first software is developed to extract dynamical model of famous dc-dc converters because at the time of this writing there is no software to obtain the converter's dynamical equation analytically. Using commercial softwares like MATLAB ${ }^{\circledR}$, only graphical frequency response of system can be obtained. Software developed here can give both analytic equation and graphical frequency response of system. Based on the dynamical equation given by software problem of controller design for two converters is studied as example. Designed controller is tested via Simulation. Authors used the developed software to train control engineering concepts to electrical engineering students. It is seen that using a power electronics converter as plant, increase electrical engineering students interest to learn control engineering concepts. Beside the educational use, developed software can be used to design controller for industrial converters.
\end{abstract}

(C) 2017 The Authors. Published by IASE. This is an open access article under the CC BY-NC-ND license (http://creativecommons.org/licenses/by-nc-nd/4.0/).

\section{Introduction}

Feedback control systems is one of the important courses in aerospace engineering, chemical engineering, electrical engineering, mechanical engineering and mechatronics engineering to name a few. Feedback control systems, improve the system so the desired behavior can be observed. Although modern control engineering is a relatively new field of study, prehistoric humans use feedback control unconsciously. They add less fire wood to a blazing fire and add more fire wood to it when it wants to die out. This is exactly the logic behind negative feedback. A first course on control engineering deals with continuous Linear Time Invariant (LTI) systems. Digital control, modern control and nonlinear control courses can be taken after first course.

Many of electrical engineering courses are in relation with control engineering concepts. For example, power electronics converters need control to provide a stable output voltage. Motor drive

\footnotetext{
* Corresponding Author.

Email Address: farzin.asadi@kocaeli.edu.tr (F. Asadi) https://doi.org/10.21833/ijaas.2017.07.002

2313-626X/C 2017 The Authors. Published by IASE.

This is an open access article under the CC BY-NC-ND license

(http://creativecommons.org/licenses/by-nc-nd/4.0/)
}

systems use control to provide a constant output shaft's speed despite of change in mechanical load. Power electronics converters are nonlinear dynamical systems. They can be used to teach control engineering concepts. Electrical engineering students generally show more enthusiasm to control electrical plants. Using a power electronics converter as plant increases electrical engineering students' interest. Concepts like control input, disturbance, steady state error and overshoot can be trained more easily.

Software is developed to extract power electronics converter's dynamical equation in this paper. Using the obtained dynamical equation, controller design procedure (which is an iterative process) is trained. Designed controller is applied to the converter in Simulink ${ }^{\circledR}$ environment. Simulation results are used to test performance of system. Authors used proposed method to train both undergraduate and graduate students.

\section{Literature review}

Foundation of State Space Averaging (SSA) was laid down in Middlebrook and Cuk (1977). The first attempt to model Discontinuous Conduction Mode (DCM) is presented in. Cuk and Middlebrook (1977). Accurate small signal models for DCM operation were developed by Sun et al. (2001). A unified SSA 
based method to develop both CCM and DCM was developed by Suntio (2006). A comprehensive survey of the modeling issues can be found in Maksimovic et al. (2001). Application of different control methods to power electronics converters has been studied in many papers. For example, feedback linearization (Sanders et al., 1986), sliding mode control (Sira-Ramirez, 1987), PID control (Venkatanarayanan and Saravanan, 2014) and $\mathrm{H}_{\infty}$ design (Rodriguez et al., 2005) has been applied to Cuk converter, Linear Matrix Inequality(LMI) control has been applied to conventional boost by Reddy et al. (2015). Discrete time controller has been designed for a boost converter in Alkrunz and Yazıcı (2016). A cascade state space controller is designed for buck mode of bidirectional dc-dc converter in Ocilka and Béreš (2010). PID control of SEPIC converter is studied in Veenalakshmi et al. (2014).

\section{Modeling and designing the controller}

Modeling is the process of formulating a mathematical description of the system. Obtaining the mathematical model of system is the first step toward designing a controller in model base controller design techniques. Switching power converters are nonlinear variable structure systems. Various techniques can be found in literature to obtain a linear continuous Time Invariant (LTI) model of a DC-DC converter. The most well-known methods are: Current injected approach, circuit averaging and state space averaging (Middlebrook and Cuk, 1977; Kislovski et al., 1991; Mohan and Undeland, 2007; Vorpérian, 1990). Averaging and small signal linearization is key steps of these methods.

State space averaging described in Middlebrook and Cuk (1977) is appropriate to describe converters that work in CCM while is less suitable for converters work in DCM. The current injected method (Kislovski et al., 1991; Mohan and Undeland, 2007) can do the job of modeling in either CCM or DCM. Circuit averaging gained a lot of attention recently due to its generality (Hren and Slibar, 2005).
At the time of this writing, there is no software to extract algebraic transfer function of power electronics converters. Using available commercial softwares only a frequency response plot can be obtained. No information about location of poles and zeros are given by software so a pencil-and-paper analysis is required to obtain the algebraic transfer function of converter. Obtaining the dynamical equation of converter in presence of circuit's non idealities such as Equivalent Series Resistance (ESR) of capacitors and inductors, voltage drop of diodes, on resistance of MOSFETS is a tedious, time consuming and error prone task for pencil-andpaper analysis. If a parameter is changed, i.e. load, all the calculation must be done from scratch. Developed software can be used to extract dynamical equation of buck, boost, buck-boost, Cuk, SEPIC, fly back, forward and full bridge converters in presence of mentioned nonlinearities. Developed software can give both algebraic transfer function and frequency response plot of converter. Fig. 1 shows main menu of software. Fig. 2 shows Cuk converter analysis section of developed software.

All what must be done is entering converter's parameters. Assume a Cuk converter with the following parameters:

$\mathrm{F}_{\text {switching }}=50 \mathrm{KHz}, \mathrm{D}=0.6, \mathrm{~V}_{\text {in }}=12 \mathrm{~V}$, rinternal $=0.6 \Omega, \mathrm{L}_{1}=500 \mu \mathrm{H}$, $\mathrm{L}_{2}=700 \mu \mathrm{H}, \quad \mathrm{rL}_{1}=10 \mathrm{~m} \Omega, \quad \mathrm{rL}_{2}=21 \mathrm{~m} \Omega, \quad \mathrm{C}_{1}=20 \mu \mathrm{F}, \quad \mathrm{C}_{2}=4 \mu \mathrm{F}$ ,rC1 $=10 \mathrm{~m} \Omega, \quad \mathrm{rC}_{2}=5 \mathrm{~m} \Omega, V_{\text {Diode_on }}=0.7, \quad \mathrm{rDiode}_{\mathrm{N}}=0.05 \Omega$, $\mathrm{r}_{\text {MOSFET }}=40 \mathrm{~m} \Omega$, $\mathrm{R}_{\text {Load }}=8.1 \Omega$.

After entering these parameters, software gives the following transfer functions:

$\frac{\widetilde{\mathrm{v}}_{\mathrm{o}(\mathrm{s})}}{\widetilde{\mathrm{d}}(\mathrm{s})}=\frac{-9.099 \times 10^{9} \mathrm{~s}^{2}+3.618 \times 10^{13} \mathrm{~s}-2.99 \times 10^{17}}{\mathrm{~s}^{4}+3.228 \times 10^{4} \mathrm{~s}^{3}+4.428 \times 10^{8} \mathrm{~s}^{2}+1.8 \times 10^{12} \mathrm{~s}+6.903 \times 10^{15}}$
$\frac{\widetilde{\mathrm{V}}_{\mathrm{o}(\mathrm{s})}}{\widetilde{\mathrm{V}}_{\mathrm{in}}(\mathrm{s})}=\frac{3.143 \times 10^{10} \mathrm{~s}-8.571 \times 10^{15}}{\mathrm{~s}^{4}+3.228 \times 10^{4} \mathrm{~s}^{3}+4.428 \times 10^{8} \mathrm{~s}^{2}+1.8 \times 10^{12} \mathrm{~s}+6.903 \times 10^{15}}$

where $\tilde{v}_{0}, \tilde{\mathrm{d}}$ and $\tilde{\mathrm{v}}_{\mathrm{S}}$ show small signal output voltage, small signal duty ratio and small signal input source voltage. Here, $\tilde{\mathrm{d}}$ is control input and $\tilde{\mathrm{v}}_{s}$ is disturbance. Fig. 3 shows a schematic diagram of system.

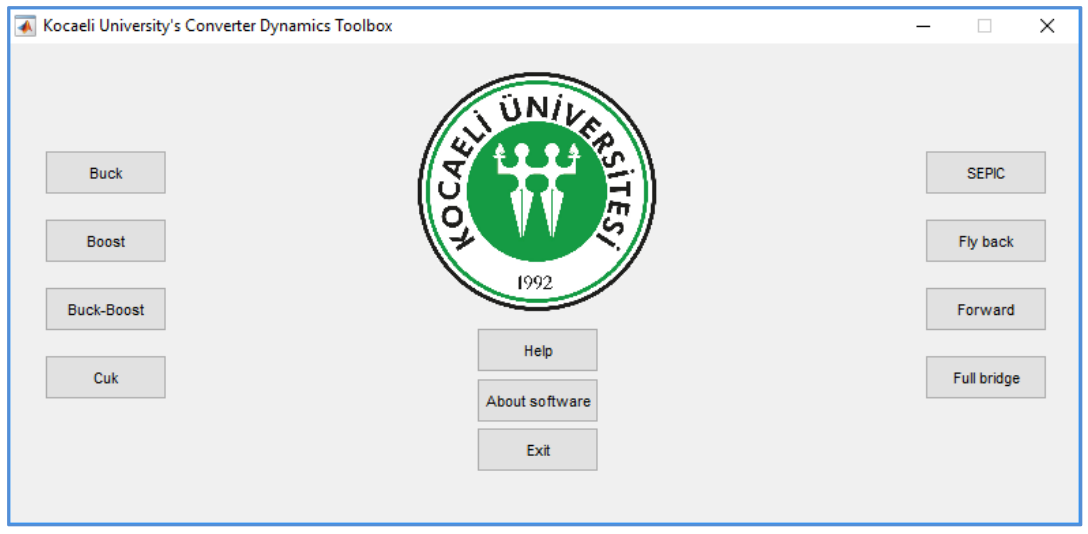

Fig. 1: Main menu of software 


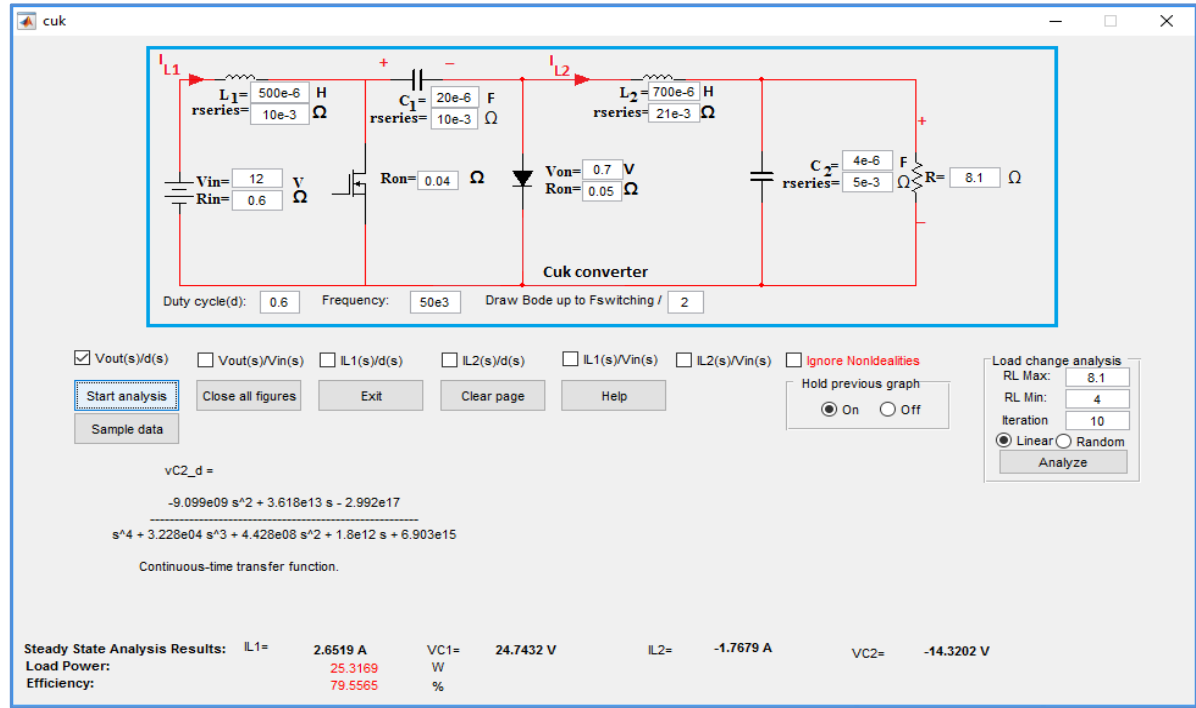

Fig. 2: Cuk converter analysis section

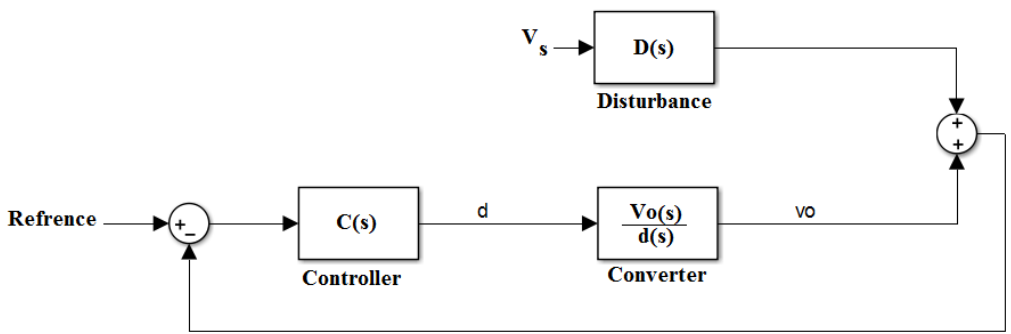

Fig. 3: Diagram of close loop system

Yet there is another source of disturbance: Output load's change. Controller tries to held output voltage constant at $V_{\text {ref }}$ despite of changes in output load or input voltage. Pole-zero diagram of $\frac{\widetilde{v}_{o(s)}}{\widetilde{d}(s)}$, its frequency response and its step is shown in Figs. 4, 5 and 6 respectively.

As shown in Fig. 4, Cuk converter is a nonminimum phase system, i.e. zeros are in Right Half Plane (RHP). Assume a PI controller of form:

$$
C(s)=K_{P}+\frac{K_{1}}{s}
$$

Loop transfer function can be written as:

$\mathrm{l}(\mathrm{s})=\mathrm{C}(\mathrm{s}) \times \frac{\widetilde{\mathrm{v}}_{\mathrm{o}(\mathrm{s})}}{\widetilde{\mathrm{d}}(\mathrm{s})}$

Close loop poles are denominator roots of $\frac{\mathrm{l}(\mathrm{s})}{\mathrm{l}(\mathrm{s})+1}$.

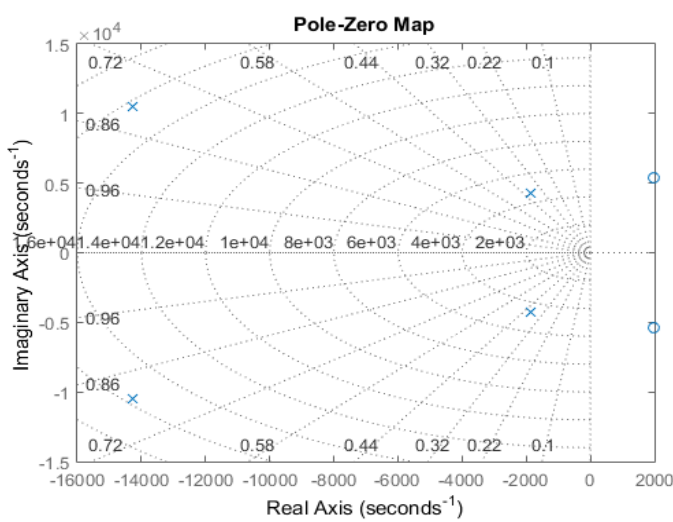

Fig. 4: Pole zero diagram of $\frac{\widetilde{v}_{o(s)}}{\widetilde{d}(s)}$

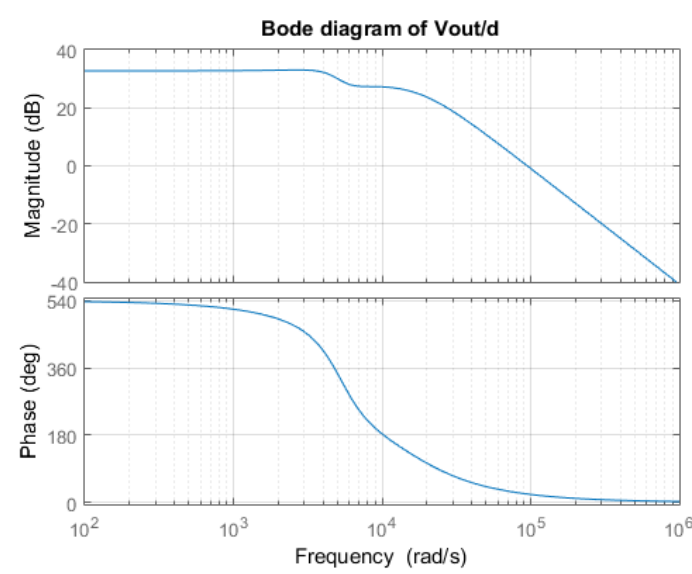

Fig. 5: Cuk converters frequency response

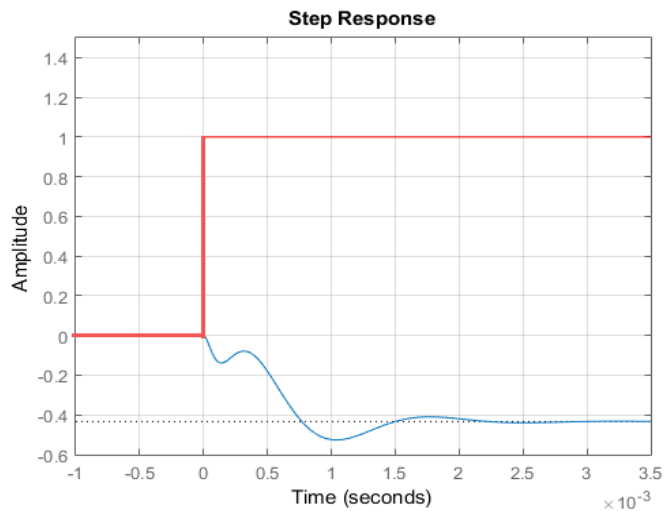

Fig. 6: Step response of $0.01 \times \frac{\widetilde{v}_{o(s)}}{\widetilde{d}(s)}$ (blue line)

Poles must lie into Left Half Plane (LHP) of complex plane for stability of system. Using Routh 
table, $\mathrm{K}_{\mathrm{P}}=0$ and $\mathrm{K}_{\mathrm{I}}<0$ ensure stability of system.

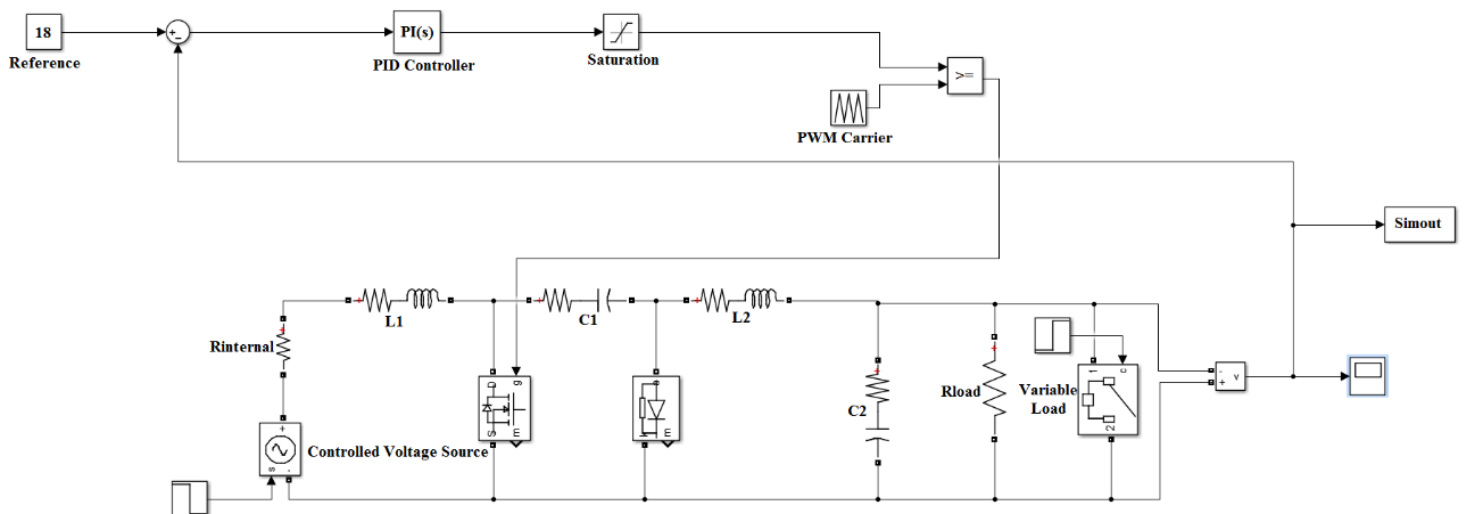

Fig. 7: Simulink diagram of Cuk converter and controller

When $\mathrm{K}_{\mathrm{P}}=-17$ close loop poles are placed at $-13760 \pm 10120 \mathrm{j}, 1830 \pm 3540 \mathrm{j} \quad$ and -1097 . Assume that load changes from $\mathrm{R}_{\text {Load }}=8.1 \Omega$ to $\mathrm{R}_{\text {Load }}=3.9 \Omega$ at $\mathrm{t}=15 \mathrm{~ms}$, input source voltage changes from $V_{s}=12 v$ to $V_{s}=18 v$ at $t=30 m s$ and reference voltage changes from Vref $=-18 \mathrm{v}$ to $\operatorname{Vref}=-12 \mathrm{v}$ at $\mathrm{t}=50 \mathrm{~ms}$. Suggested scenario is shown in Table 1.

Table 1: Test scenario for Cuk converter

\begin{tabular}{ccccc}
\hline Change in ... & \multirow{2}{*}{ Time } & Initial value & Final value & $\frac{\text { final }- \text { inital }}{\text { initial }} \times 100 \%$ \\
\hline Rload & $15 \mathrm{~ms}$ & $8.1 \Omega$ & $3.9 \Omega$ & -51.8 \\
Vs & $30 \mathrm{~ms}$ & $12 \mathrm{v}$ & $18 \mathrm{v}$ & 33.3 \\
Vref & $50 \mathrm{~ms}$ & $-18 \mathrm{v}$ & $-12 \mathrm{v}$ & 33.3 \\
\hline
\end{tabular}

Fig. 8 shows simulation results of the aforementioned scenario.

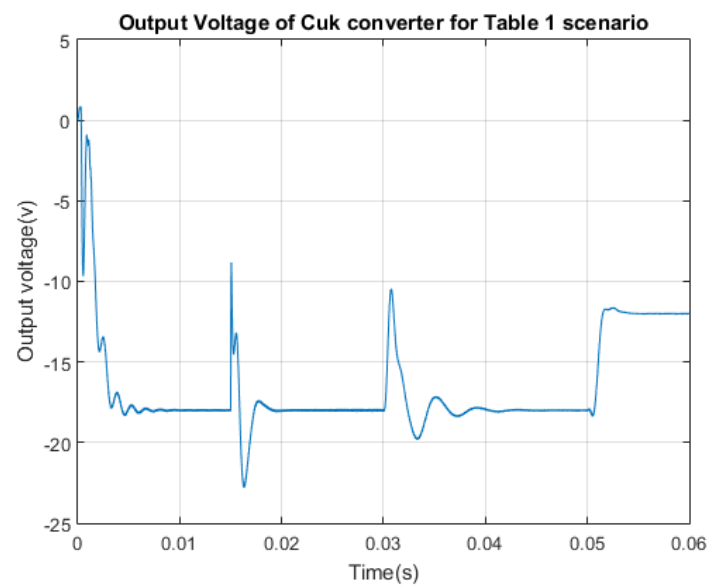

Fig. 8: Simulation result of Table 1 scenario

Controller can keep output voltage constant despite of change in input source voltage or load. Also, system tracks a step reference signal with zero steady state error, which is expected due to presence of integrator. Bode plot of

$\mathrm{l}(\mathrm{s})=\mathrm{C}(\mathrm{s}) \times \frac{\widetilde{\mathrm{v}}_{\mathrm{o}(\mathrm{s})}}{\widetilde{\mathrm{d}}(\mathrm{s})}$

is shown in Fig. 9. Phase margin is 73.6 Degrees and gain margin is $12.4 \mathrm{~dB}$. Cross over frequency is 117.8 $\mathrm{Hz}$.

Fig. 10 shows controller step response for different values of load in the range $3.9 \Omega$ to $8.1 \Omega$. As seen settling time approximately changes from $5 \mathrm{~ms}$ to $10 \mathrm{~ms}$.
As another example, assume problem of controlling a buck converter with the following parameters:

$F_{\text {switching }}=25 \mathrm{KHz}, \quad D=0.4, \quad V_{\text {in }}=50 \mathrm{v}, \quad r_{\text {internal }}=1 \Omega, L=400 \mu \mathrm{H}$, $\mathrm{rL}=5 \mathrm{~m} \Omega, \mathrm{C}=100 \mu \mathrm{F}, \mathrm{rC}=10 \mathrm{~m} \Omega, V_{\text {Diode_on }}=0.7$, r Diode_on $=0.05 \Omega$, $\mathrm{r}_{\text {MOSFET }}=40 \mathrm{~m} \Omega$, $\mathrm{R}_{\text {Load }}=10 \Omega$.

After entering above values to developed software frequency response of converter $\left(\frac{\widetilde{v}_{o(s)}}{\widetilde{d}(s)}\right)$ is obtained as shown in Fig. 11.

Applying the $\mathrm{K}$ factor method (Venable, 1983; Basso, 2008) to Fig. 8, following controller is obtained:

$\mathrm{C}(\mathrm{s})=14.11 \times \frac{\mathrm{s}+0.0002}{\mathrm{~s} \times(\mathrm{s}+0.00016)}$

Fig. 12 shows Simulink diagram of system with designed controller. Result of simulating the scenario shown in Table 2 is shown in Fig. 13.

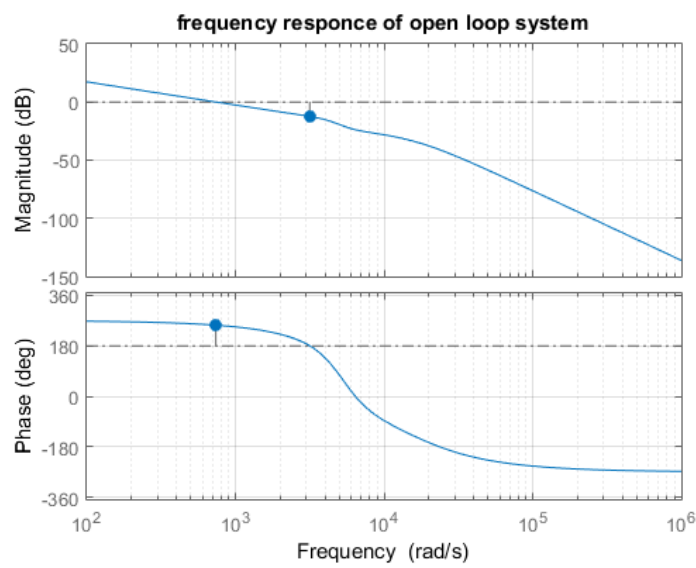

Fig. 9: Open loop frequency response of Cuk converter and designed controller 


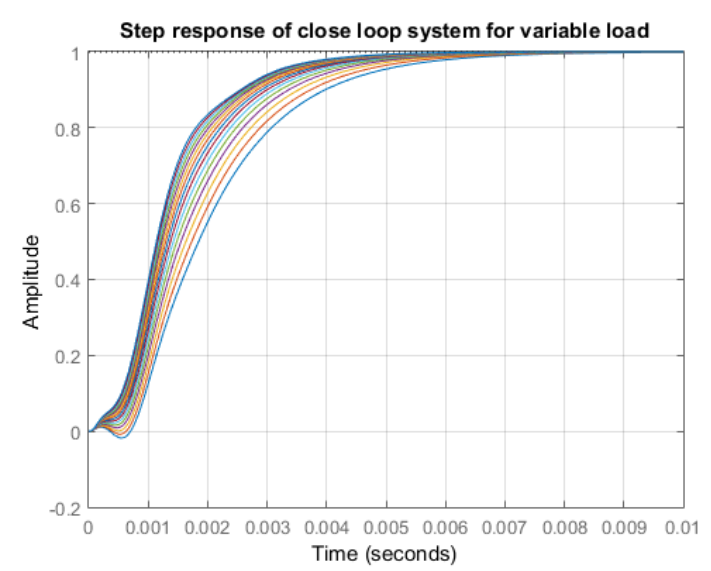

Fig. 10: Close loop response for different values of $\mathrm{R}_{\text {load }}$

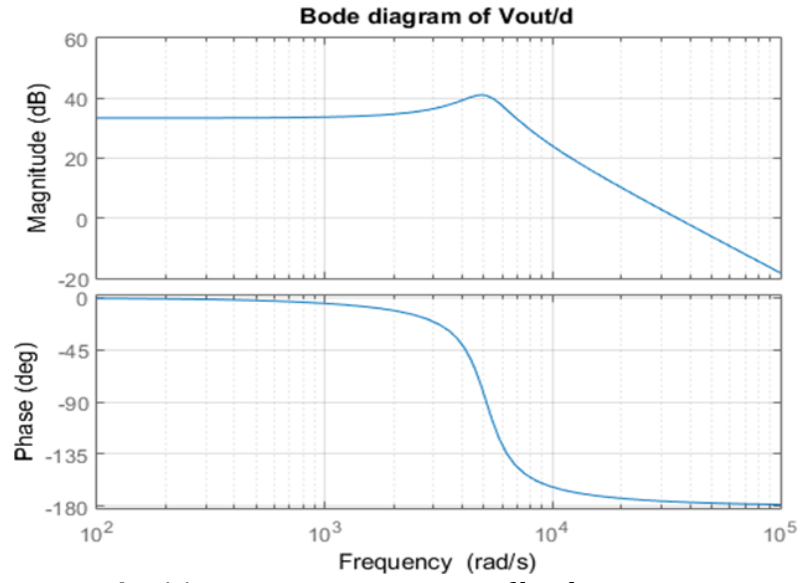

Fig. 11: Frequency response of buck converter

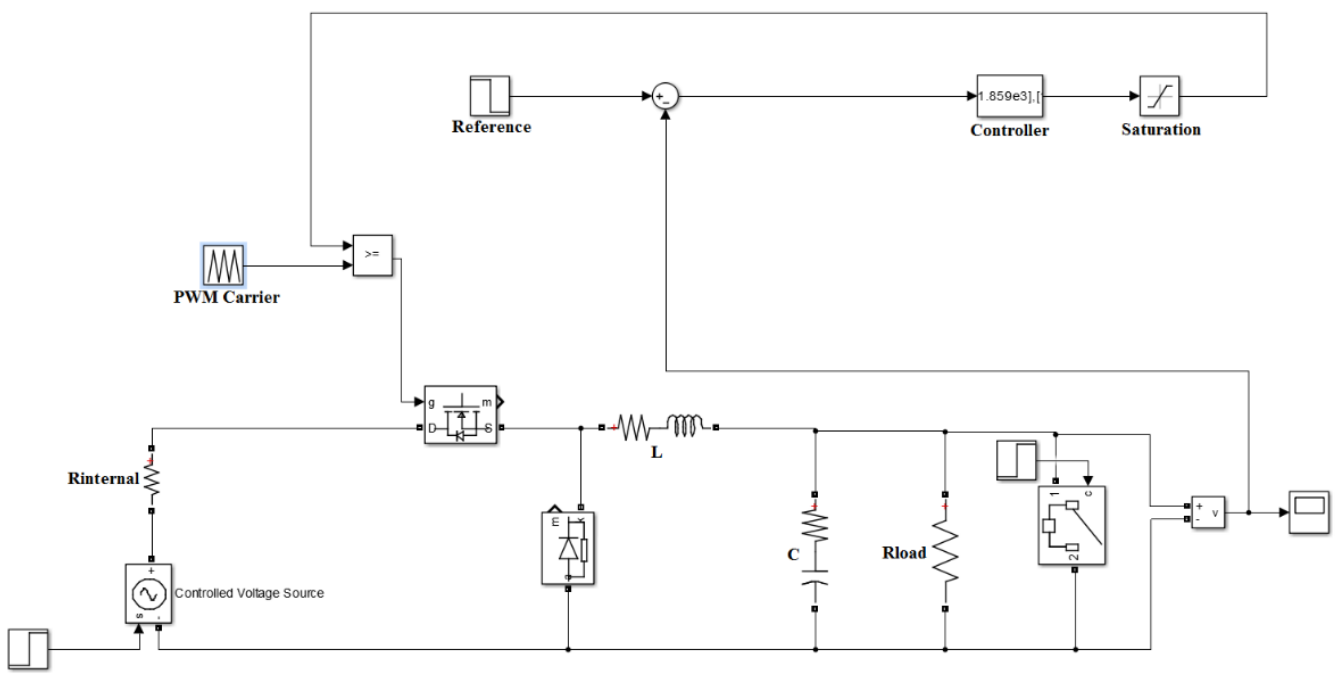

Fig. 12: Simulink diagram of buck converter with designed controller

Table 2: Test scenario for buck converter

\begin{tabular}{ccccc}
\hline Change in $\ldots$ & \multirow{2}{*}{ Time } & Initial value & Final value & $\frac{\text { final }- \text { inital }}{\text { initial }} \times 100 \%$ \\
\hline Rload & $15 \mathrm{~ms}$ & $10 \Omega$ & $4.47 \Omega$ & -55.3 \\
Vs & $30 \mathrm{~ms}$ & $50 \mathrm{v}$ & $40 \mathrm{v}$ & -20 \\
Vref & $50 \mathrm{~ms}$ & $20 \mathrm{v}$ & $25 \mathrm{v}$ & 25 \\
\hline
\end{tabular}

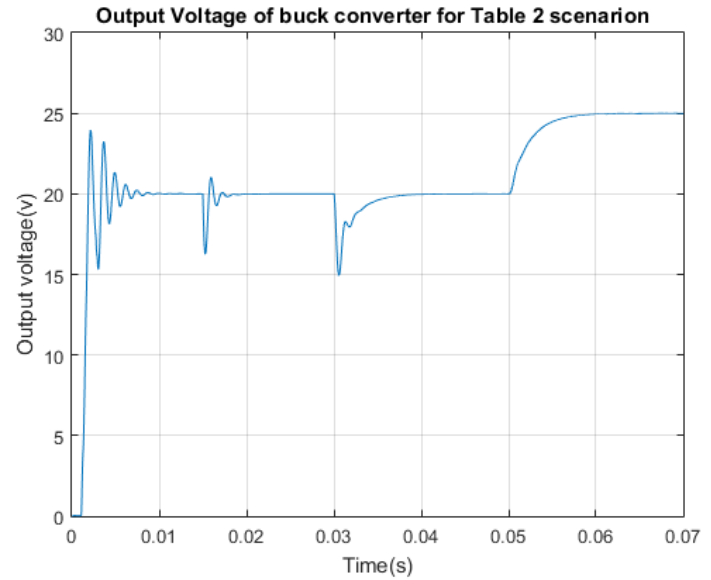

Fig. 13: Simulation result of Table 2's scenario

\section{Conclusion}

Control engineering is one of the important courses in many fields of study. Although, control engineering texts provide plenty of examples and exercises taken from different disciplines, nonelectrical plants make no sense for electrical engineering students in general. Using power electronics converters as plant increases student's interest to learn. In this paper software is developed to do the boring process of the converter's modeling. After modeling phase, a controller can be designed. Beside the educational aims, developed software can be used to solve industrial problems.

\section{References}

Alkrunz M and Yazıcı I (2016). Design of discrete time controllers for the DC-DC boost converter. SAÜ Fen Bilimleri Enstitüsü Dergisi, 20 (1): 75-82. Available online at: http://dergipark.gov.tr/saufenbilder/issue/20706/221215

Basso C (2008). Switch-mode power supplies. McGraw-Hill, New York, USA.

Cuk S and Middlebrook R (1977). A general unified approach to modelling switching dc-to-dc converters in discontinuous conduction mode. In the IEEE Conference on Power 
Electronics Specialists, IEEE, Palo Alto, USA: 36-57. https://doi.org/10.1109/PESC.1977.7070802

Hren A and Slibar P (2005). Full order dynamic model of SEPIC converter. In the IEEE International Conference on Industrial Electronics, IEEE. Palo Alto, USA: 2: 553-558. https://doi.org/10.1109/PESC.1977.7070802

Kislovski AS, Redl R, and Sokal NO (1991). Dynamic analysis of switching-mode DC/DC converters. Design Automation Inc., Lexington, USA.

Maksimovic D, Stankovic AM, Thottuvelil VJ, and Verghese GC (2001). Modeling and simulation of power electronic converters. Proceedings of the IEEE, 89(6): 898-912.

Middlebrook RD and Cuk S (1977). A general unified approach to modelling switching-converter power stages. International Journal of Electronics Theoretical and Experimental, 42(6): 521-550.

Mohan N and Undeland TM (2007). Power electronics: Converters, applications, and design. John Wiley \& Sons, New York, USA.

Ocilka M and Béreš $T$ (2010). State space controller for bidirectional dc-dc converter buck mode. In the 10th Scientific Conference of Young Researchers, Kosice, Slovakia. Available online at: web.tuke.sk/scyr/data/upload/1268677728.pdf

Reddy PRK, Kumar SG, Sandeep K, and Arun N (2015). L MI control of conventional boost converter. Indian Journal of Science and Technology, 8(S2): 50-52.

Rodriguez H, Ortega R, and Astolfi A (2005). Adaptive partial state feedback control of the DC-to-DC Cuk converter. In the
Conference of American Control, IEEE. Portland, USA: 51215126. https://doi.org/10.1109/ACC.2005.1470832

Sanders SR, Varghese GC, and Cameron DF (1986). Nonlinear control laws for switching power converters. In the $25^{\text {th }}$ IEEE Conference on Decision and Control, IEEE, Athens, Greece: 25: 46-53. https://doi.org/10.1109/CDC.1986.267131

Sira-Ramirez H (1987). Sliding motions in bilinear switched networks. IEEE Transactions on Circuits and Systems, 34(8): 919-933.

Sun J, Mitchell DM, Greuel MF, Krein PT, and Bass RM (2001). Averaged modeling of PWM converters operating in discontinuous conduction mode. IEEE Transactions on Power Electronics, 16(4): 482-492.

Suntio T (2006). Unified average and small-signal modeling of direct-on-time control. IEEE Transactions on Industrial Electronics, 53(1): 287-295.

Veenalakshmi S, Pugazhenthi PN, and Selvaperumal S (2014). Power electronics and integrated control circuits. In: Selvaperumal S, Nagarajan R, and Pugazhenthi N (Eds.), Applied Mechanics and Materials. Trans Tech Publications, Zurich, Switzerland: 573: 161-166.

Venkatanarayanan S and Saravanan M (2014). Proportion integral control for SEPIC converter. Reseach Journal of Applied Sciences Engineering and Technology, 8(5): 623-629.

Vorpérian V (1990). Simplified analysis of PWM converters using model of PWM switch. II. Discontinuous conduction mode. IEEE Transactions on Aerospace and Electronic Systems, 26(3): 497-505. 